\title{
Relationship between Locations of Facial Injury and the Use of Bicycle Helmets: A Systematic Review
}

\author{
Kun Hwang ${ }^{1}$, Yun Moon Jeon ${ }^{2}$, Yeong Seung $\mathrm{Ko}^{2}$, Yeon Soo Kim ${ }^{1}$ \\ ${ }^{1}$ Department of Plastic Surgery, ${ }^{2}$ Inha University School of Medicine, Incheon, Korea
}

The aim of this study is to review the protective effect of a bicycle helmet on each facial location systematically. PubMed was searched for articles published before December 12, 2014. The data were summarized, and the odds ratio (OR) between the locations of facial injury was calculated. A statistical analysis was performed with Review Manager (The Nordic Cochrane Centre). Bicycle helmets protect the upper and middle face from serious facial injury but do not protect the lower face. Non-wearers had significantly increased risks of upper facial injury $(O R, 2.07 ; P<0.001)$ and of middle facial injury $(O R, 1.97 ; P<0.001)$ as compared to helmet users. In the case of lower facial injury, however, only a slightly increased risk (OR, 1.42; 95\% confidence interval $(\mathrm{Cl}), 0.67-3.00, \mathrm{P}=0.36$ ) was observed. The abovementioned results can be attributed to the fact that a helmet covers the head and forehead but cannot cover the lower face. However, helmets having a chin cap might decrease the risk of lower facial injury.

Keywords: Bicycling / Head protective devices / Facial injury
Correspondence: Kun Hwang Department of Plastic Surgery, Inha University School of Medicine, 27 Inhang-ro, Jung-gu, Incheon 400-711, Korea

Tel: $+82-32-890-3514$

Fax: +82-32-890-2918

E-mail: jokerhg@inha.ac.kr

No potential conflict of interest relevant to this article was reported.

\section{INTRODUCTION}

Previous studies have reported that wearing a bicycle helmet reduces the risks of facial injury and head injury [1-3].

However, there are few papers that provide the ratio of people who wear a bicycle helmet and the incidence of injury. In fact, a previous study reported that bicycle helmets could reduce the risk of injury in the upper and middle facial region but provided no protection to the lower facial region $[4,5]$.

The aim of this study is to review the protective effects of a bicycle helmet on each facial location systematically.

\section{METHODS}

For helmet use and location of facial injury, the search terms "facial trauma OR facial injury OR facial location" AND "helmet OR bicycle helmet OR cycling helmet OR head protective device" were used in a PubMed search, which resulted in 417 papers (Fig. 1).

Studies that did not include an evaluation of the relationship between bicycle helmet use and the location of any facial injury were excluded. No restrictions on language and publication forms were imposed. All the articles were read by two independent reviewers who extracted data from the articles. 
The data were summarized and the odds ratio (hereafter, OR) between the locations of facial injury were calculated. A statistical analysis was performed with Review Manager (The Nordic Cochrane Centre).

\section{RESULTS}

Among the 417 titles, we found 22 potentially relevant articles, from which 4 papers met our inclusion criteria (Fig. 1).

\section{Helmet use and location of facial injury}

Upper facial injury vs. non-facial injury

Two studies were sub-grouped, and a meta-analysis of their data suggested that there is a significantly increased risk of upper facial injury (except abrasions or contusions) for non-users as com-

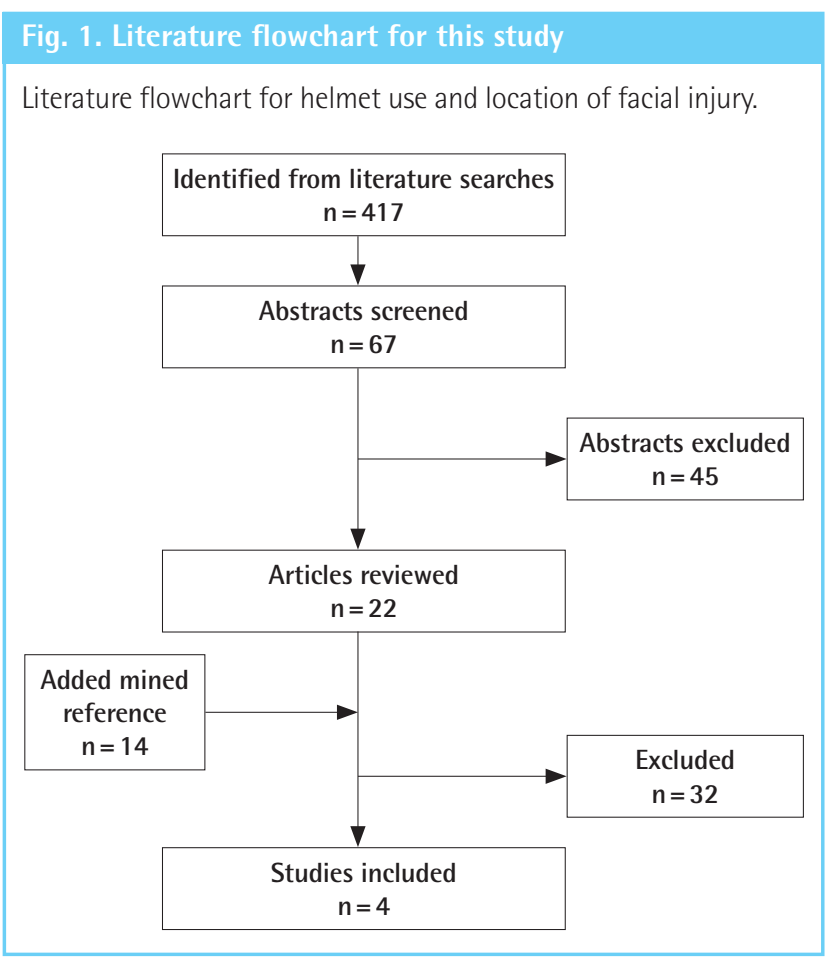

pared to helmet users $(n=2,836$; OR, 2.07; 95\% confidence interval $[\mathrm{CI}], 1.55-2.78 ; \mathrm{Z}=4.89, \mathrm{P}<0.001$, heterogeneity: chi $\left.^{2}=0.05, \mathrm{I}^{2}=0 \%\right)($ Table 1, Fig. 2A) $[4,5]$.

Middle facial injury versus non-facial injury

Two studies were sub-grouped and a meta-analysis of their data suggested that there is a significantly increased risk of middle facial injury in non-users as compared to helmet users $(n=2,710$, $\mathrm{OR}=1.97,95 \% \mathrm{CI}=1.42-2.74, \mathrm{Z}=4.05, \mathrm{P}<0.001$, heterogeneity: $\mathrm{Chi}^{2}=0.01, \mathrm{I}^{2}=0 \%$ ) (Table 1, Fig. 2B) $[4,5]$.

\section{Lower facial injury versus non-facial injury}

Two studies were sub-grouped and a meta-analysis of their data suggested that there is a slightly increased risk of lower facial injury in non-users as compared to helmet users $(n=3,198$; OR, 1.42; 95\% CI, 0.67-3.00; $\mathrm{Z}=0.91 ; \mathrm{P}=0.36$; heterogeneity, $\mathrm{Chi}^{2}$ $\left.=5.84, \mathrm{I}^{2}=82 \%\right)($ Table 1, Fig. $2 \mathrm{C})[4,5]$.

\section{DISCUSSION}

Facial injury occurs in 43 out of 100,000 accident cases in the United States [4]. In the present study, the facial protection effect of a helmet varied according to the face location analyzed.

Non-users had a significantly increased risk of upper facial injury (OR, 2.07; $\mathrm{P}<0.001)$ and of middle facial injury (OR, 1.97; $\mathrm{P}<0.001)$ as compared to helmet users. In the case of lower facial injury, however, only a slightly increased risk (OR, 1.42; 95\% CI, 0.67-3.00; P = 0.36) was observed. In other words, bicycle helmets protect the upper and middle face from serious facial injury but not the lower face.

The abovementioned result can be attributed to the fact that a helmet typically covers the head and forehead but does not cover the lower face. Further, despite the fact that most helmets cannot directly protect the middle face, we observed that the risk of middle facial injury could be reduced significantly by wearing a helmet $(\mathrm{OR}=1.97, \mathrm{P}<0.001)$. This observation could be at-

Table 1. Helmet use and location of facial injury

\begin{tabular}{|c|c|c|c|c|c|c|c|c|}
\hline \multirow{2}{*}{ Author (yr) } & \multirow{2}{*}{ Patients } & \multirow{2}{*}{$\begin{array}{l}\text { Facial } \\
\text { injury }\end{array}$} & \multicolumn{3}{|c|}{ Facial injury } & \multirow{2}{*}{$\begin{array}{l}\text { Other } \\
\text { injury }\end{array}$} & \multicolumn{2}{|c|}{$\%$ of helmet users } \\
\hline & & & Upper & Middle & Lower & & Facial injury & Other injury \\
\hline Thompson et al. (1990) [4] & 531 & 318 & $35(12)^{a)}$ & $133(41)^{\mathrm{a})}$ & $150(109)^{a)}$ & 319 & 14.20 & 26 \\
\hline Thompson et al. (1996) [5] & 2,909 & 908 & 506 & 141 & 561 & 2,209 & $\begin{array}{r}\text { UFI: } 35.4 \\
\text { MFI: } 36.9 \\
\text { LFI: } 52.9\end{array}$ & 53.40 \\
\hline Acton et al. (1996) [6] & 813 & 340 & 91 & 95 & 154 & 492 & 55.14 & - \\
\hline Lima et al. (2012) [7] & 556 & 311 (facial fracture) & 4 & 154 & 153 & - & 6 & - \\
\hline
\end{tabular}




\section{Fig. 2. Helmet use and location of facial injury}

(A) Upper facial injury versus non-facial injury, (B) Middle facial injury versus non-facial injury, (C) Lower facial injury versus non-facial injury.

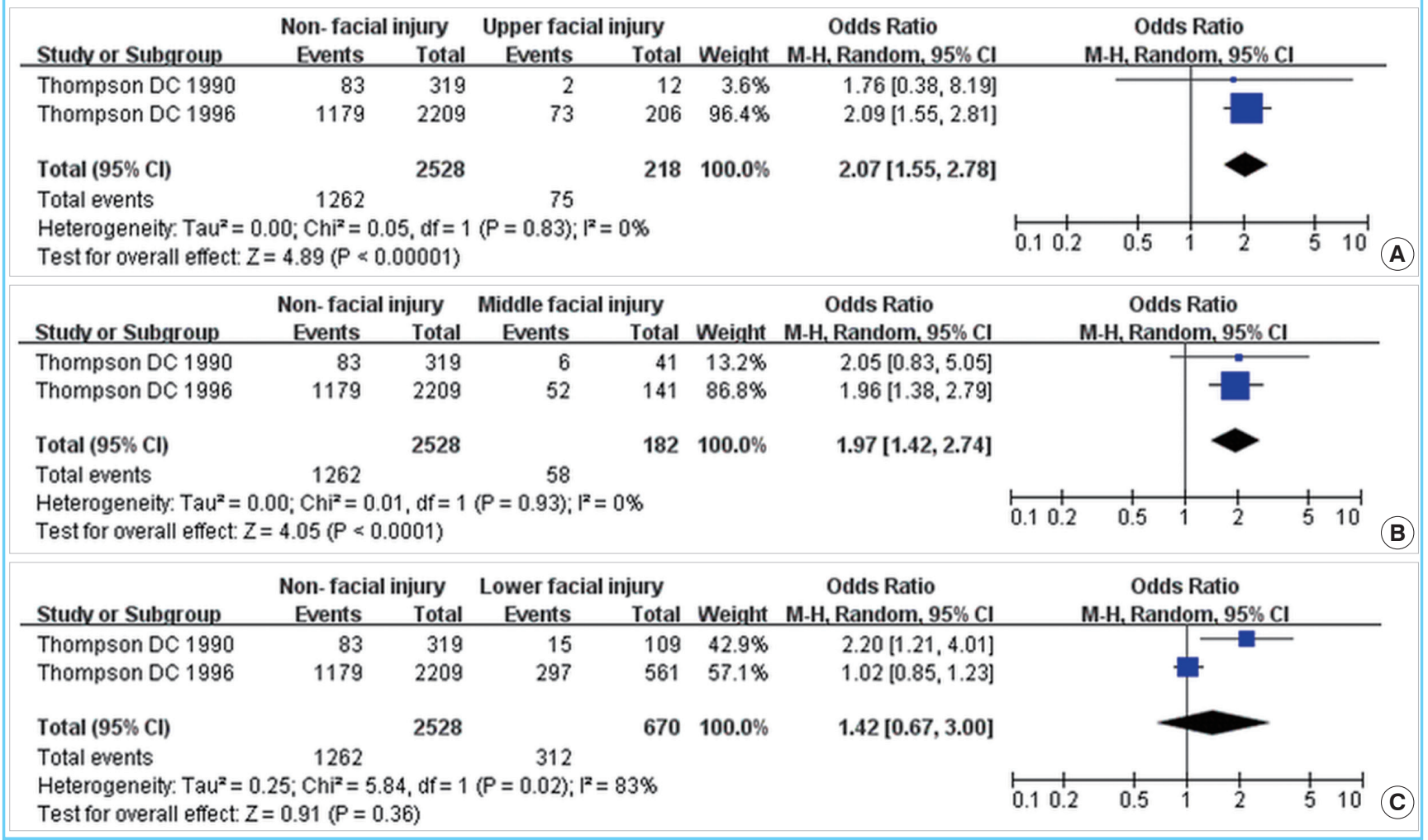

\section{Fig. 3. Middle face protecting effect of the helmet}

Mechanism of the middle face protecting effect of the helmet. When the rider falls down, the helmet peak (P) comes into contact with the ground before the middle face.

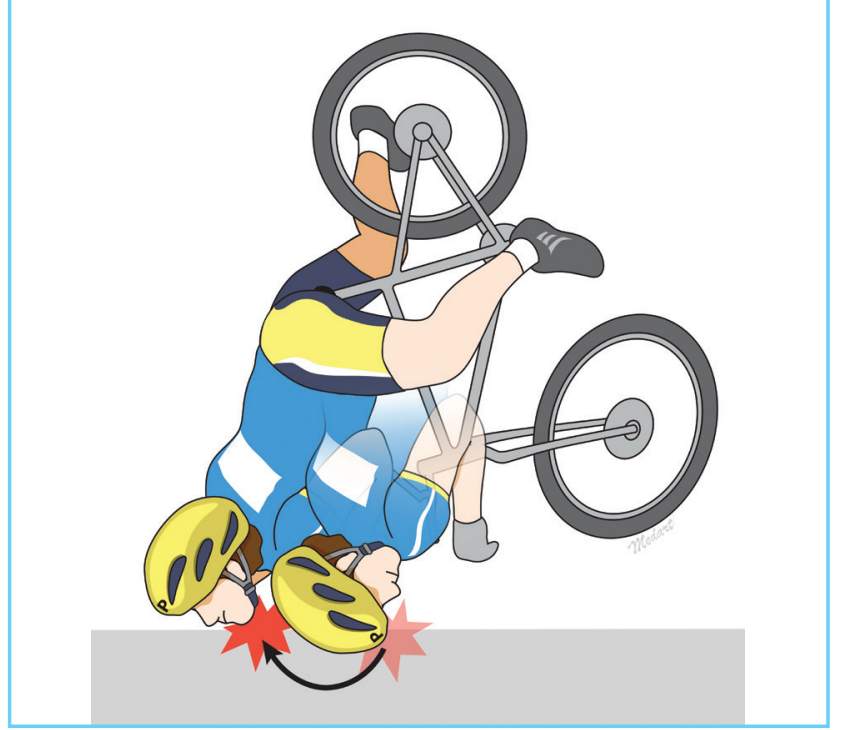

tributed to the following: first, because the helmet peak changes the angle of the second impact, when the rider is falling down, the helmet that covers the head and upper face comes into con- tact with the ground before the middle face (Fig. 3). Second, since the helmet directly protects the upper face, the severity of the nearby middle face injury could also be lowered by wearing a helmet.

Further, we agree with Thompson et al. [4] and Acton et al. [6] that wearing a helmet having a chin cap might decrease the risk of lower facial injury.

The facial injuries that Acton et al. [6] and Lima et al. [7] considered were classified as upper, middle, and lower. However, we could not find a control group in Lima's paper nor could we find helmet use as a percentage in Acton's paper [6,7]. Therefore, we could not consider these two papers in the meta-analysis.

In conclusion, bicycle helmets protect the upper and middle face from serious facial injury but not the lower face.

\section{REFERENCES}

1. McDermott FT, Lane JC, Brazenor GA, et al. The effectiveness of bicyclist helmets: a study of 1710 casualties. J Trauma 1993;34:834-44.

2. Heng KW, Lee AH, Zhu S, et al. Helmet use and bicycle-related trauma in patients presenting to an acute hospital in Singapore. Singapore Med J 2006;47:367-72. 
3. Wasserman RC, Buccini RV. Helmet protection from head injuries among recreational bicyclists. Am J Sports Med 1990; 18:96-7.

4. Thompson DC, Thompson RS, Rivara FP, et al. A case-control study of the effectiveness of bicycle safety helmets in preventing facial injury. Am J Public Health 1990;80:1471-4.

5. Thompson DC, Nunn ME, Thompson RS, et al. Effectiveness of bicycle safety helmets in preventing serious facial in- jury. JAMA 1996;276:1974-5.

6. Acton $\mathrm{CH}$, Nixon JW, Clark RC. Bicycle riding and oral/maxillofacial trauma in young children. Med J Aust 1996;165: 249-51.

7. Lima SM, Santos SE, Kluppel LE, et al. A comparison of motorcycle and bicycle accidents in oral and maxillofacial trauma. J Oral Maxillofac Surg 2012;70:577-83. 